This is an electronic reprint of the original article. This reprint may differ from the original in pagination and typographic detail.

Author(s): Kirppu, Heidi; Lahdelma, Risto; Salminen, Pekka

Title: $\quad$ Multicriteria evaluation of carbon-neutral heat-only production technologies for district heating

Year: $\quad 2018$

Version:

Please cite the original version:

Kirppu, H., Lahdelma, R., \& Salminen, P. (2018). Multicriteria evaluation of carbonneutral heat-only production technologies for district heating. Applied Thermal Engineering, 130, 466-476. https://doi.org/10.1016/j.applthermaleng.2017.10.161

All material supplied via JYX is protected by copyright and other intellectual property rights, and duplication or sale of all or part of any of the repository collections is not permitted, except that material may be duplicated by you for your research use or educational purposes in electronic or print form. You must obtain permission for any other use. Electronic or print copies may not be offered, whether for sale or otherwise to anyone who is not an authorised user. 


\section{Accepted Manuscript}

Multicriteria evaluation of carbon-neutral heat-only production technologies for district heating

Heidi Kirppu, Risto Lahdelma, Pekka Salminen

PII:

S1359-4311(17)31409-6

DOI: https://doi.org/10.1016/j.applthermaleng.2017.10.161

Reference: ATE 11360

To appear in:

Applied Thermal Engineering

\section{APPLIED}

THERMAL

ENGINEERING

1 March 2017

Received Date:

22 September 2017

Revised Date:

30 October 2017

Accepted Date:

Please cite this article as: H. Kirppu, R. Lahdelma, P. Salminen, Multicriteria evaluation of carbon-neutral heatonly production technologies for district heating, Applied Thermal Engineering (2017), doi: https://doi.org/10.1016/ j.applthermaleng.2017.10.161

This is a PDF file of an unedited manuscript that has been accepted for publication. As a service to our customers we are providing this early version of the manuscript. The manuscript will undergo copyediting, typesetting, and review of the resulting proof before it is published in its final form. Please note that during the production process errors may be discovered which could affect the content, and all legal disclaimers that apply to the journal pertain. 


\title{
Multicriteria evaluation of carbon-neutral heat-only production technologies for district heating
}

\author{
Heidi Kirppu ${ }^{1}$, Risto Lahdelma ${ }^{2,3}$ and Pekka Salminen ${ }^{4 *}$ \\ ${ }^{1}$ Helen Ltd. \\ Kampinkuja 2, 00090 HELEN, Finland \\ Email: heidi.kirppu@helen.fi \\ ${ }^{2}$ Aalto University School of Engineering, \\ Department of Mechanical Engineering, \\ Otakaari 4, FIN-02015 Aalto, Finland \\ Email: risto.lahdelma@aalto.fi \\ ${ }^{3}$ Aalto University School of Science, \\ Department of Mathematics and Systems Analysis, \\ Otakaari 1, FIN-02015 Aalto, Finland \\ Email: risto.lahdelma@aalto.fi \\ ${ }^{4}$ University of Jyväskylä, School of Business and Economics, \\ P.O. Box 35, FIN- 40014 University of Jyväskylä, Finland \\ Email: pekka.o.salminen@jyu.fi \\ *Corresponding author
}

\begin{abstract}
Climate change mitigation requires reducing dependence on fossil fuels and transition to low carbon energy production technologies. Nearly half of the global final energy consumption is thermal energy produced from technologies with high carbon dioxide emission. As such, it is imperative to employ carbon-neutral heat production to achieve a sustainable energy system.

This paper presents a real-life case of applying multicriteria decision analysis for evaluating carbonneutral heat-only production technologies in a major district heating system in Finland. A group of 10 experts from the energy company contributed in defining the alternative technologies and multiple economic, technological, and environmental evaluation criteria. The experts also provided the criteria measurements and preference information for different criteria. The alternatives were compared using Stochastic Multicriteria Acceptability Analysis (SMAA). SMAA is a simulation based method for decision problems where different kind of uncertain information is represented by probability distributions. Because the preferences of the experts were highly conflicting, the SMAA method was extended within this study to treat conflicting preferences.
\end{abstract}

The most preferred alternatives were short-term heat storages and electric boilers based on renewable power. These alternatives may be considered attractive future solutions particularly in balancing peak load heat consumption and production.

\section{Keywords}

Carbon-neutral, district heating, heat-only production, multicriteria decision analysis, SMAA 


\section{Highlights}

- Heat storages and electric boilers are best solutions for peak-load situations

- CCS technology is too immature, unreliable, costly, and has too large space demand

- Solar heat is unfavorable at Helsinki latitude due to bad coincidence with demand

- Multicriteria method was developed for treating conflicting experts' preferences

\section{Introduction}

\subsection{Background}

The design of future energy systems generally aims at reaching acceptable levels of carbon dioxide $\left(\mathrm{CO}_{2}\right)$ emission. The common approach is by increasing energy efficiency and integrating carbonneutral or renewable energy sources in the energy system to a greater extent, as indicated in many studies (Lund et al. 2010). Carbon-neutral means that the technology emits no or very little $\mathrm{CO}_{2}$. A number of studies have aimed at the design of future 100 percent renewable energy systems (Østergaard et al. 2010). However, these studies often focus on electricity production and overlook the role of thermal energy. A number of recent studies, including Heat Roadmap Europe (Connolly et al. 2014), have recognised the role of thermal energy production in the efforts to reduce emissions of the energy sector. In fact, nearly half of the global final energy consumption is thermal energy.

The demand for thermal energy, such as heating and cooling fluctuates greatly both within the day and between different seasons. For this reason the production capacity needs to be flexible enough to satisfy the demand. Many renewable energy sources, such as wind power, solar power, and solar heat are intermittent. Increasing the share of such energy sources is making it more challenging to balance the supply and demand for thermal energy.

District heating (DH) has in several studies been considered the most energy efficient and environment friendly heating system in cities, as the heating network enables improvements in the overall energy efficiency with the use of any available heat source including waste and surplus heat from other industrial processes (Lund et al. 2014). Besides, the DH network allows more costefficient integration of renewable energy into the energy system (Ghafghazi et al. 2010b).

This study evaluates different carbon-neutral heat production technologies for the district heating and cooling (DHC) system of the city of Helsinki, capital of Finland. The DH system covers over $90 \%$ of the heat demand and operates with over $90 \%$ energy efficiency. Currently over $90 \%$ of the $\mathrm{DH}$ production is based on efficient combined heat and power $(\mathrm{CHP})$ production, using different fuels, such as natural gas, coal, and biomass. In addition, large scale heat pumps are applied for coproduction of DHC. The possible carbon-neutral heat production technologies for Helsinki include different types of biomass combustion, solar heat, geothermal heat, heat pumps, electric heating, and carbon capture and storage (CCS). The decision between the different technology options must consider many local conditions and objectives. Therefore, we applied multicriteria decision analysis (MCDA) in the selection process.

In this study the Stochastic Multicriteria Acceptability Analysis (SMAA) method was used for analysing the suitability of different renewable and carbon-neutral heat-only production alternatives for DH. The case study considered the existing DH system of the city of Helsinki, which also aims to become carbon-neutral in the long term because of national and international climate policy. 
Therefore, the objective of this study was to identify the most suitable carbon-neutral heat-only production technologies for DH considering particularly the technical, economic and environmental points of view. In addition, significant aspects to consider were energy security and the supply during peak demand.

Both criteria measurements and preferences were provided by a group of experts. Because the experts provided partly conflicting information, as methodological novelty, a new way to treat such information in SMAA was developed in this study.

\subsection{Literature review}

MCDA methods have recently become more employed in sustainable energy planning problems. Several earlier MCDA studies have concerned different aspects of power systems. These include site selection for hydropower (Omitaomu et al. 2012, Vučijak et al. 2013), solar power (Mamlook et al. 2001, Cavallaro 2009), wind power (Sánchez-Lozano et al. 2016), production technology evaluations (Pilavachi et al. 2011), selection of prime mover for organic Rankine cycle (Khorasaninejad et al. 2016), community level power solutions (Cherni et al. 2007, Grujić et al. 2014, Rahman et al. 2013), and large scale power system analyses (Ribeiro et al. 2013, Matteson 2014, Maxim 2014, Santoyo-Castelazo \& Azapagic 2014, Stein 2013). Mixed heat and power system analyses include definition of the general sustainability index to measure the sustainability of an urban energy system by Jovanovic et al. (2010), MCDA model for evaluating renewable energy technologies for the island of Crete by Tsoutsos et al. (2009), sustainability ranking of renewable power and heat generation technologies by Dombi et al. (2014), MCDA evaluation of multi-source energy systems by Catalina et al. (2011). Combined heat and power (CHP) systems analyses include evolutionary multicriteria optimization of fuel cell-gas turbine combined cycle by Burer et al. (2003), evaluation of CHP technologies in terms of energy, economy and environmental points of view by Wang et al. (2015a), and selection of residential energy energy supply system by Alanne et al. (2007).

MCDA for heating systems include both building level studies (Chinese et al. 2011, Wang 2015) and community level analyses (Mroz 2008, Ghafghazi et al. 2010a, Kontu et al. 2015). Reviews about using MCDA methods for sustainable energy planning can be found in Pohekar \& Ramachandran (2004), Wang et al. (2009), Si et al. (2016), Kumar et al. (2017) and Mardani et al. (2017).

SMAA method was introduced by Lahdelma et al. (1998) and developed further by Lahdelma \& Salminen (2001), Lahdelma et al. (2003), and Lahdelma \& Salminen (2010). SMAA was developed for decision problems where the criteria measurements and preference information can be uncertain, inaccurate or even partly missing. SMAA is a simulation based method, where different kinds of uncertain information are represented by probability distributions. SMAA computes statistically for each alternative the probabilities to obtain each rank. The computation is implemented by MonteCarlo simulation, where values for the uncertain variables are sampled from their distributions and alternatives are evaluated by applying the decision model (Tervonen \& Lahdelma 2007). The recommended solution is typically the alternative with highest probability for the first rank. However, the probabilities for other possible solutions are also provided for the decision makers (DMs). This means that SMAA describes how robust the model is subject to different uncertainties in the input data (Lahdelma \& Salminen 2012, 2016). For a survey on SMAA methods, see Tervonen \& Figueira (2008). 
SMAA has been applied to many problems in the areas of municipal planning (Hokkanen et al. 1998), harbor development (Hokkanen et al. 1999), polluted soil remediation (Hokkanen et al. 2000; Lahdelma et al. 2001; Lahdelma \& Salminen 2008a), waste treatment plant siting (Lahdelma et al. 2002), forest management (Kangas et al. 2003, 2005, 2006), waste storage area siting (Lahdelma \& Salminen 2008b), risk-based classification of nanomaterials (Tervonen et al. 2009); multimodal cargo hub development (Menou et al. 2010), strategic environmental assessment (Rocchi 2012), rural electrification in developing countries (Rahman et al. 2013), energy policy assessment (Rahman et al. 2016), benefit-risk analysis of drugs (Tervonen et al. 2011; van Valkenhoef et al. 2012; Okul et al. 2014), energy monitoring systems selection (Pesola et al. 2014), dredged material management (Scheffler et al. 2014), peak heating plant siting in DH system (Wang et al. 2015b), residential heating alternative evaluation (Kontu et al. 2015), and public sector facility selection (Karabay et al. 2016).

\section{Decision Problem}

The studied case concerned the DH system in the city of Helsinki, the capital of Finland. The DHC system in Helsinki is operated by Helen Ltd (Helen), which is the former municipal energy company of Helsinki and now a limited company fully owned by the city of Helsinki. The city of Helsinki and Helen have a long-term objective to become carbon-neutral by the year of 2050 (Helen Ltd. 2015a). The current DH production system consists of 3 combined heating and power (CHP) plants fuelled with coal, natural gas, and biomass, 10 heat-only plants fuelled with natural gas and oil, and a large scale combined heating and cooling heat pump plant using municipal treated wastewater, passive solar heat, and seawater as heating and cooling sources. The DH network in Helsinki is presented in Figure 1. (Helen Ltd. 2015b)

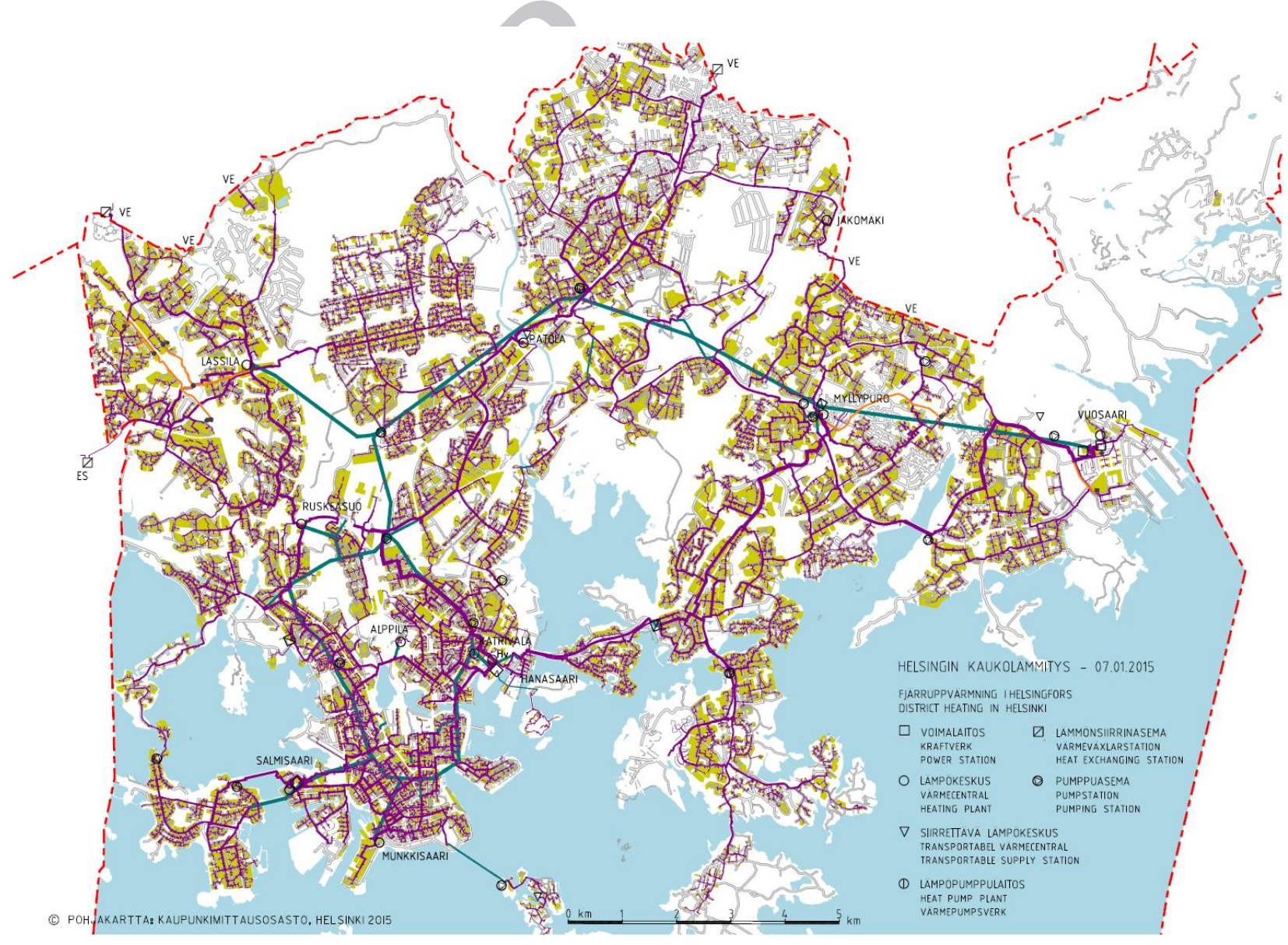


Figure 1. The DH network of Helsinki (Helen Ltd. 2015c). DH pipes in red, DH tunnels in blue.

Over 90 percent of the city building stock or about 132 million $\mathrm{m}^{3}$ is heated by $\mathrm{DH}$. The total length of the DH lines is over $1300 \mathrm{~km}$. The annual demand of DH varies between 6000-7000 GWh. Depending on the yearly variations, approximately 90 percent of the $\mathrm{DH}$ is produced energyefficient in CHP plants, which serve primarily as base-load plants. (Helen Ltd. 2015d) However the $\mathrm{DH}$ capacity for the case of peak heat demand needs to be significantly larger, since the DH demand is strongly dependent on seasonal variations. Thus there is also a need for relatively large capacity of peak heat plants, which are rarely used. The City Council of Helsinki has decided to decommission one of the CHP plants, which is currently fuelled by coal and biomass, and to release the area for urban planning (Helen Ltd. 2015e).

Accordingly, there is a need for new carbon-neutral energy production capacity that is technically, economically and environmentally feasible in the specific conditions of Helsinki. Helsinki has notable urban population growth and land use is largely designed for residential areas. There is limited space for power and heating plants. Helsinki coastal area by the Baltic Sea has northern climate. The heating season for a normal year is from September to May, but the DH system operates year-round because hot household water is also produced using DH in Finland. Growing city, improving energy-efficiency of buildings, and warming climate with increasing unpredictable seasonal variations are also affecting the city's heat demand. Therefore, this study aims to find feasible DH production technologies to fulfil the future carbon-neutral objective. The DM in this study is Helen Ltd., but the city of Helsinki must still approve the decision. For this reason, it is necessary to consider criteria other than $\mathrm{CO}_{2}$ emissions and costs.

The alternative carbon-neutral heat production technologies were evaluated in a multicriteria decision aiding process. First, several possible technologies were surveyed and selected for the study. Then, evaluation criteria were determined. Special emphasis was given for production during the peak heat demand, since it defines the capacity requirement for the entire DH production system. After that, criteria measurements and preference information were collected from experts.

\subsection{Experts}

A group of 10 energy experts from Helen participated in the process. The experts were chosen on the basis that they hold at least at Master's level academic degree in the field of energy and working experience from 5 years to over 20 years in the energy industry. They also work at different departments representing different sectors of Helen, including DHC production, DHC customer service and sales, new energy production development, energy systems optimization, environmental and social responsibility, and engineering \& design of energy plants. The intention of expert selection was to incorporate a broad set of points of view to the decision process. The experts provided their information anonymously and independently in order to gain their unaffected opinions. Based on the collected information, the alternatives were evaluated using SMAA.

\subsection{Alternatives}

A wide selection of possible heat production technologies were initially surveyed by a literature review. The aim was to include all currently identified carbon-neutral technologies which may be feasible in the case of Helsinki at the present or in the future. Infeasible alternatives for Helsinki were excluded. Helsinki for example, lacks industry that produces high temperature surplus heat. Also no excess waste incineration material is available. Selection and more detailed determination of alternatives were then carried out in cooperation with the experts. The alternative heat-only 
production technologies are described briefly in the subsequent paragraphs, and summarized in Table 1.

- Biomass combustion: Wood chips are the least processed forest industry by-products and commonly available. Wood chips can be efficiently combusted in boilers that are suitable for relatively moist biomass, such as fluidized bed boilers (A1). Bubbling (BFB) or circulating (CFB) fluidized bed boilers are also flexible with the fuel. These boilers can combust mixed biomass fuel and biomass residues such as wood chips, waste wood, and agricultural residues (A2). Grate boilers (A3) are a traditional and simpler type of boilers, and consequently less expensive and less efficient for wood chip combustion. Grate boiler also enables mixed biomass fuel combustion (A4). Forest biomass can also be processed into more easily combustible fuels. Biogas can be produced locally in a gasifier through a thermal gasification process of forest biomass and combusted in a conventional gas boiler (A5). Alternatively, high-quality biogas can be produced remotely and transported via a gas network to be used in existing gas boilers without any modifications (A6). Wood pellets consist of milled and compressed forest residues that can be combusted efficiently in pulverized fuel boiler (A7). Refined pellets (A8), e.g. torrefied or steam exploded wood pellets i.e. biocoal, are highly processed biomass fuels with properties more similar to coal. Refined pellets can also be used in pulverized fuel boilers. Biomass-to-liquid processes typically tend to aim at biofuels, like biodiesel, having comparable properties to fuel oil allowing combustion in a conventional existing oil boiler (A9). Pyrolysis oil (A10) is produced in the pyrolysis process of forest biomass. The properties of pyrolysis oil require some modifications to the standard oil boiler and the combustion process itself.

- Solar heat: Solar heat plant consists of a field of solar collectors. The system can include underground seasonal storage (A11) to balance the seasonal variations in the heat supply. Alternatively, the solar heat plant can be provided with a short-term storage (A12) such as a water tank. Solar heat plant can also be configured to operate without any specific storage (A13) by utilizing existing storages and the storage capacity of the district heating network itself.

- Geothermal heat: Enhanced geothermal systems (A14) can utilize the heat from deep lowtemperature geothermal reservoirs. The water is pumped to the deep borehole in the ground where it heats up to about $120^{\circ} \mathrm{C}$. The heated water flows up through another borehole and the heat can be transferred directly to the district heating network through a heat exchanger. In Finland, suitable depth is estimated to be about 6-7 km and the technology is still in the stage of development. Such a pilot plant is currently being constructed in the neighboring city of Espoo (St1 2016).

- Heat pumps: Heat pumps absorb heat from a source of lower temperature and upgrade it to higher temperature. Heat pumps are carbon-neutral only if the electricity they use is carbonneutral. The ratio between produced heat and consumed power is the COP (Coefficient of Performance) factor of the heat pump. Ground source heat pumps (A15) for large scale production require a field of heat-wells (100-300 $\mathrm{m}$ deep). Typical COP factor is 3; accordingly one third of the produced heat is from electricity and two thirds from the ground. Sea water source heat pumps (A16) produce heat with a typical COP factor of 2.5 from cold sea water that is a few degrees above zero. Heat pumps also enable the use of low temperature surplus heat from industry and services (A17) by upgrading it to higher temperature heat. 
- Heat storages: Short-term heat storages (A18) are typically water tanks, and can be used for meeting the peak heat demand and cutting the peak loads. Thus, they replace part of the peak heat production. Seasonal heat storages (A19) are long-term heat storages that can be used for balancing the seasonal variations in the supply. Typical long-term heat storage considered here is a cavern in bedrock.

- Electric heating: Electric boilers (A20) using carbon-neutral generated electricity can produce carbon-neutral district heat with almost $100 \%$ efficiency. The increase of variable electricity production requires more flexibility between the energy networks. In case of overproduction of variable renewable power, excess electricity can be used for producing heat which can be more easily stored. Electric boiler can also serve as a quick peak and back-up heat boiler.

- Carbon capture and storage: Carbon capture and storage (CCS) (A21) can be applied to existing fossil fuel plants. Using CCS it is possible to continue using the existing plants with fossil fuels, and avoid the $\mathrm{CO}_{2}$ emissions to the atmosphere. Retrofitting CCS system to an existing plant, as well as $\mathrm{CO}_{2}$ transportation and storage, might require significant modifications and can be costly or difficult, as the technology is still in the stage of development. Finland does not have suitable storage sites for $\mathrm{CO}_{2}$, which means that the captured $\mathrm{CO}_{2}$ needs to be transported by ship elsewhere. 
Table 1. Alternative heat production technologies.

\section{Biomass combustion}

A1

A2

A3

A4

A5

A6

A7

A8

A9

A10

Solar heat

A11

A12

A13

Combustion of wood chips in fluidized bed boiler

Mixed fuel combustion in bubbling fluidized bed boiler

Combustion of wood chips in grate boiler

Mixed fuel combustion in grate boiler

Thermal gasification of forest biomass and combustion in gas boiler

Combustion of biogas in gas boiler (gas transported via gas network)

Wood pellet combustion in pulverized fuel boiler

Refined pellets or biocoal combustion in pulverized fuel boiler

Combustion of biodiesel in oil boiler

Combustion of pyrolysis oil in oil boiler (retrofit)

Solar heat plant with underground (heat pump assisted) seasonal storage

Solar heat plant with short-term storage

\section{Geothermal heat}

A14 Enhanced geothermal heat plant (6-7 km deep low-temperature reservoir)

Heat pumps

A15

A16

Ground source heat pump on heat-well field

A17

Sea water source heat pump

Low temperature surplus heat, heat pump (industry, services, ...)

\section{Heat storages}

A18 Short-term heat storage (water tank)

A19 Seasonal heat storage (cavern in bedrock)

Electric heating

A20 Electric boiler (using carbon-neutral power)

Carbon capture and storage

A21 CCS applied at current plants

\subsection{Criteria}

The selection of criteria in MCDA is ultimately determined by the DM (Lahdelma et al. 2000). In this case, Helen wanted to consider various economic, technical and environmental criteria. The intention was to satisfy the general requirement on criteria in MCDA listed by Keeney and Raiffa (1976):

- Completeness: all the important points of view of the problem are covered.

- Operationality: the set of criteria can be measured and used meaningfully in the analysis.

- Non-redundancy: two or more criteria should not measure the same thing.

- Minimality: the dimension of the problem should be kept to a minimum.

Literature review was used to identify a long list of possible criteria (Wang et al. 2009), among which the relevant ones for the current problem were chosen in collaboration with experts from Helen.

Two economy-related criteria were included, the investment cost and levelized cost of heat. The levelized cost of heat is the net present value of the investment and operations \& maintenance costs divided by the discounted heat production over the lifetime. There is some overlap between the two cost criteria. However, the DM wanted to see these two costs separately in the analysis, because different weightings between these two criteria are possible. Because DH business is a natural 
monopoly whose operation is regulated, pricing of heat must follow cost correlation and be uniform for all customers. This means that revenues are not a criterion in the problem.

From the technical point of view, it was considered particularly important to support production during the peak heat demand. For this reason several criteria focus on desired characteristics to support peak heat production. The peak load assumption affects also the planned operation of the production technologies, and consequently assessment of the operating costs and environmental impacts. Technical criteria included in the analysis were availability, storability, flexibility, and maturity of technology. Availability measures how well the energy source is available at different times. Availability is important from security of supply point of view, because Helen must supply $\mathrm{DH}$ to meet the demand at all times. Several renewable energy forms have shortcomings in availability. For example, very little solar energy is available during the cold season when DH is needed the most. Storability can refer to storing the fuel or the produced heat. Storability is important, because it helps meeting the fluctuating heat demand. Good storability can compensate for poor availability. Compared to fossil fuels, biomass requires more storage space and degrades faster over time. Storing heat in form of hot water or by heating up the bedrock is relatively simple and cheap compared to storing electric power. Flexibility measures how energy production can be started, adjusted and operated on partial load to meet the fluctuating demand in different operating situations. Maturity measures the stage of technology development and it correlates with the reliability of the technology. Reliability is important because DH supply must not be interrupted at any time. For mature heat production technologies, the level of reliability is well known, and in general very good. For early stage technologies, there is little evidence of the reliability in production use.

A commonly used technical criterion in sustainable energy decision making is efficiency. This analysis does not include the efficiency criterion explicitly, but efficiency is considered indirectly all costs and environmental criteria, because these are defined in relation to production volume or capacity.

Environmental criteria chosen for this analysis were space requirement, logistics, reduction in $\mathrm{CO}_{2}$ emissions, and reduction in other emissions. Small space requirement is beneficial in a dense urban environment. Similarly, alternatives requiring little transportation logistics are advantageous in the city. Although all alternatives are considered carbon-neutral, there is still some variation in the $\mathrm{CO}_{2}$ emission reductions. Depending on which fossil fuel based production forms (coal, oil, natural gas) can be replaced by carbon-neutral production, the $\mathrm{CO}_{2}$ emission reduction will be larger or smaller. Each carbon-neutral alternative may also cause small direct or indirect emissions. Also other emissions, such as SOx, NOx, and particulate emissions, should be as small as possible. Alternatives that require no fuel or electric power have in general smaller emissions.

The criteria considered in this study are presented in Table 2. 
Table 2. Criteria for evaluating carbon-neutral heat-only production technologies for DH.

\begin{tabular}{|l|l|}
\hline Criteria & Description \\
\hline Costs & \\
\hline C1 Investment cost & Cost of initial investment for technology per capacity. \\
\hline C2 Levelized cost of heat & Overall cost of heat production per production volume. \\
\hline Technical & \\
\hline T1 Availability & Availability of energy source at different times. \\
\hline T2 Storability & The ease of storing fuel or heat with minimal losses. \\
\hline T3 Flexibility & Fast-response adjustment of production volume. \\
\hline T4 Maturity & The stage of technology development as indicator of reliability. \\
\hline Environmental & \\
\hline E1 Space requirement & The additional space required per plant capacity. \\
\hline E2 Logistics & The additional logistical requirements of the technology. \\
\hline E3 CO 2 emissions & The degree of reduction in $\mathrm{CO}_{2}$ emission of the technology. \\
\hline E4 Other emissions & Other emissions caused or reduced by the technology. \\
\hline
\end{tabular}

\subsection{Criteria measurements}

All criteria were evaluated on subjective linear scales from 1 to 9 , where 1 is the best value. This facilitated using the linear value function in the MCDA analysis. Subjective scales were chosen, because natural scales do not exist for some of the criteria (e.g. the technical criteria). Also, subjective evaluation was more appropriate for some early stage technologies, such as deep geothermal heat and CCS. The group of 10 experts (described in section 2.1) assessed criteria measurements for all alternatives. Each expert provided their criteria measurements independently by answering of a query form. The query described the case, the alternatives, and the criteria. The experts were instructed to answer the form column-wise, so that they could compare all alternatives with respect to each criterion, in turn. This approach improves the consistency of the answers because then the expert can easily verify that alternatives obtain the intended preference order with respect to each criterion. If the experts did not consider themselves to know some technology well enough, they could leave that row blank. One of the experts did not evaluate A20 and another expert declined from evaluating A10 and A15. Table 3 shows the average evaluations and their standard deviations. Uniform distributions around the average measurement plus minus standard deviation were used in the multicriteria analysis. 
Table 3. Criteria measurements for alternatives (expected value \pm standard deviation).

$\begin{array}{lcccccccccc}\text { AltlCrit } & \text { C1 } & \text { C2 } & \text { T1 } & \text { T2 } & \text { T3 } & \text { T4 } & \text { E1 } & \text { E2 } & \text { E3 } & \text { E4 } \\ \text { A1 } & 5.4 \pm 0.9 & 3.6 \pm 1.0 & 2.7 \pm 1.3 & 4.6 \pm 2.1 & 3.5 \pm 1.4 & 1.2 \pm 0.4 & 4.6 \pm 1.6 & 6.9 \pm 0.9 & 2.6 \pm 1.3 & 4.9 \pm 2.3 \\ \text { A2 } & 6.2 \pm 1.5 & 3.9 \pm 1.3 & 2.8 \pm 1.0 & 4.8 \pm 1.9 & 3.7 \pm 1.3 & 1.6 \pm 1.0 & 5.0 \pm 1.7 & 7.1 \pm 1.0 & 2.8 \pm 1.3 & 5.1 \pm 2.2 \\ \text { A3 } & 4.4 \pm 1.2 & 3.6 \pm 1.3 & 2.7 \pm 1.3 & 4.6 \pm 2.1 & 3.7 \pm 1.6 & 1.3 \pm 0.4 & 4.7 \pm 1.4 & 6.9 \pm 0.9 & 2.5 \pm 1.4 & 5.0 \pm 2.3 \\ \text { A4 } & 4.9 \pm 1.3 & 3.9 \pm 1.6 & 2.7 \pm 1.3 & 4.7 \pm 2.0 & 3.8 \pm 1.6 & 1.4 \pm 0.7 & 5.2 \pm 1.4 & 7.0 \pm 0.8 & 2.6 \pm 1.3 & 5.1 \pm 2.2 \\ \text { A5 } & 6.7 \pm 1.3 & 5.1 \pm 2.0 & 2.7 \pm 1.3 & 4.7 \pm 1.7 & 4.4 \pm 0.9 & 3.5 \pm 1.6 & 5.2 \pm 1.6 & 6.5 \pm 1.7 & 3.0 \pm 1.2 & 4.3 \pm 1.6 \\ \text { A6 } & 3.5 \pm 2.8 & 5.6 \pm 1.6 & 4.9 \pm 2.5 & 4.3 \pm 2.0 & 2.1 \pm 0.6 & 2.0 \pm 2.2 & 1.6 \pm 0.7 & 2.3 \pm 1.7 & 3.2 \pm 1.7 & 3.7 \pm 2.2 \\ \text { A7 } & 4.0 \pm 1.0 & 4.1 \pm 1.3 & 2.6 \pm 0.6 & 3.8 \pm 0.7 & 2.9 \pm 0.8 & 2.1 \pm 0.7 & 3.4 \pm 1.1 & 5.3 \pm 1.3 & 3.0 \pm 1.3 & 4.6 \pm 1.9 \\ \text { A8 } & 5.0 \pm 1.6 & 5.3 \pm 1.7 & 5.6 \pm 2.5 & 3.4 \pm 1.5 & 3.1 \pm 1.0 & 4.6 \pm 2.0 & 3.1 \pm 0.8 & 4.9 \pm 1.4 & 3.5 \pm 1.5 & 4.8 \pm 1.8 \\ \text { A9 } & 2.7 \pm 1.4 & 6.2 \pm 2.0 & 4.2 \pm 1.8 & 2.4 \pm 1.5 & 1.8 \pm 0.6 & 1.7 \pm 1.2 & 2.0 \pm 0.7 & 3.5 \pm 1.5 & 3.9 \pm 2.0 & 3.8 \pm 1.2 \\ \text { A10 } & 4.2 \pm 1.8 & 6.4 \pm 1.4 & 5.4 \pm 2.1 & 4.6 \pm 2.7 & 2.7 \pm 1.3 & 4.3 \pm 1.7 & 2.9 \pm 1.2 & 3.3 \pm 1.0 & 3.8 \pm 1.4 & 4.6 \pm 1.8 \\ \text { A11 } & 7.1 \pm 1.1 & 5.5 \pm 2.4 & 5.9 \pm 1.5 & 6.0 \pm 2.0 & 5.4 \pm 1.9 & 3.5 \pm 1.6 & 7.3 \pm 0.6 & 1.4 \pm 0.7 & 3.1 \pm 2.0 & 1.8 \pm 1.9 \\ \text { A12 } & 6.3 \pm 1.5 & 4.8 \pm 2.6 & 7.5 \pm 0.8 & 6.7 \pm 1.4 & 6.0 \pm 2.3 & 2.7 \pm 1.7 & 6.8 \pm 1.3 & 1.2 \pm 0.4 & 2.7 \pm 1.8 & 1.9 \pm 2.2 \\ \text { A13 } & 5.9 \pm 2.2 & 4.9 \pm 2.9 & 8.2 \pm 0.9 & 8.9 \pm 0.3 & 8.9 \pm 0.3 & 2.2 \pm 1.6 & 6.8 \pm 1.6 & 1.2 \pm 0.4 & 2.9 \pm 1.9 & 1.9 \pm 2.2 \\ \text { A14 } & 7.5 \pm 1.6 & 4.4 \pm 2.2 & 3.9 \pm 2.3 & 3.9 \pm 2.6 & 4.5 \pm 2.7 & 8.4 \pm 0.7 & 3.0 \pm 1.3 & 1.2 \pm 0.4 & 2.6 \pm 2.0 & 1.3 \pm 0.5 \\ \text { A15 } & 5.4 \pm 1.6 & 3.6 \pm 1.3 & 2.8 \pm 1.0 & 3.7 \pm 1.9 & 4.0 \pm 2.1 & 1.7 \pm 1.3 & 5.0 \pm 1.4 & 1.3 \pm 0.5 & 3.4 \pm 1.7 & 1.9 \pm 0.8 \\ \text { A16 } & 6.0 \pm 1.8 & 4.2 \pm 1.9 & 5.1 \pm 1.2 & 4.5 \pm 2.3 & 4.6 \pm 1.6 & 2.0 \pm 1.2 & 3.8 \pm 1.2 & 1.4 \pm 0.7 & 4.0 \pm 1.5 & 2.0 \pm 1.0 \\ \text { A17 } & 4.4 \pm 1.9 & 3.9 \pm 1.7 & 4.6 \pm 1.8 & 6.4 \pm 1.5 & 7.0 \pm 1.7 & 2.5 \pm 1.6 & 3.4 \pm 1.5 & 1.7 \pm 0.9 & 3.6 \pm 1.8 & 2.0 \pm 1.3 \\ \text { A18 } & 3.5 \pm 1.9 & 3.2 \pm 2.0 & 3.8 \pm 1.6 & 3.4 \pm 1.4 & 2.0 \pm 1.1 & 1.2 \pm 0.4 & 3.6 \pm 1.9 & 1.2 \pm 0.4 & 4.5 \pm 2.1 & 1.9 \pm 1.3 \\ \text { A19 } & 5.5 \pm 1.6 & 3.9 \pm 1.4 & 4.3 \pm 2.1 & 3.2 \pm 1.6 & 2.7 \pm 1.4 & 3.8 \pm 2.2 & 4.6 \pm 1.8 & 1.3 \pm 0.5 & 4.6 \pm 2.3 & 2.0 \pm 1.2 \\ \text { A20 } & 2.8 \pm 1.6 & 5.8 \pm 2.1 & 2.0 \pm 1.6 & 4.3 \pm 2.3 & 1.2 \pm 0.4 & 1.3 \pm 0.7 & 2.1 \pm 1.0 & 1.2 \pm 0.4 & 3.8 \pm 2.9 & 2.9 \pm 2.1 \\ \text { A21 } & 9.0 \pm 0.0 & 8.6 \pm 0.7 & 6.6 \pm 2.9 & 6.9 \pm 1.6 & 6.2 \pm 1.7 & 8.7 \pm 0.7 & 7.2 \pm 1.3 & 5.1 \pm 2.2 & 4.4 \pm 3.1 & 4.0 \pm 2.0\end{array}$

\subsection{Preference information}

Each expert was asked to assess the importance of the criteria by giving the most important criterion rank 1 , the following criterion rank 2 , etc. The assessment of criteria rankings considered the variation between the best and worst score. If the experts could not determine the order of preference for some criteria, they could assign them same rank. Table 4 shows the order of preference for criteria by 9 experts (one of the 10 experts did not provide preference information). The question mark denotes unspecified order of preference. As can be seen from the table, each expert provided a different order of preference. Thus, the subjective preference information of different experts is conflicting. This is natural because the experts represent different sectors, and therefore they emphasize different points of view.

Table 4. Order of preference for criteria given by the nine (9) experts.

\section{Expert No. Order of Preference}

\begin{tabular}{|c|c|}
\hline & $\mathrm{C} 1 ? \mathrm{C} 2 ?$ ? 2 ? $\mathrm{T} 3 \quad$ ? $\mathrm{T} 4 \succ \mathrm{T} 1 \succ \mathrm{E} 1 \succ \mathrm{E} 3 ? \mathrm{E} 4 \succ \mathrm{E}$ \\
\hline 2 & $\mathrm{C} 2 \succ \mathrm{C} 1 \succ \mathrm{T} 1 \succ \mathrm{E} 3 \succ \mathrm{T} 3 \succ \mathrm{T} 4 \succ \mathrm{E} 4 \succ \mathrm{T} 2 \succ \mathrm{E} 2 \succ \mathrm{E} 1$ \\
\hline 3 & $\mathrm{C} 1$ ? $\mathrm{C} 2 \quad$ ? $\mathrm{T} 1 \succ \mathrm{E} 3 \succ \mathrm{T} 2 \quad$ ? $\mathrm{E} 2 \succ \mathrm{T} 3 \quad$ ? $\mathrm{E} 1 \succ \mathrm{T} 4 \succ \mathrm{E} 4$ \\
\hline 4 & $\mathrm{C} 1 ?$ ? $4 \succ \mathrm{C} 2$ ? $\mathrm{T} 1 \quad$ ? $\mathrm{T} 2$ ? $\mathrm{T} 3 \succ \mathrm{E} 3 \succ \mathrm{E} 2 \succ \mathrm{E} 4 \succ \mathrm{E} 1$ \\
\hline 5 & $\mathrm{~T} 1 \succ \mathrm{T} 2 \succ \mathrm{C} 2 \succ \mathrm{E} 3 \succ \mathrm{T} 4 \succ \mathrm{T} 3 \succ \mathrm{E} 1 \succ \mathrm{E} 4 \succ \mathrm{C} 1 \succ \mathrm{E}$ \\
\hline 6 & $\mathrm{~T} 4 \succ \mathrm{C} 2 \succ \mathrm{C} 1 \succ \mathrm{T} 1 \succ \mathrm{E} 3 \succ \mathrm{E} 4 \succ \mathrm{T} 3 \succ \mathrm{T} 2 \succ \mathrm{E} 1 \succ \mathrm{E}$ \\
\hline 7 & $\mathrm{C} 2 \succ \mathrm{T} 3 \succ \mathrm{T} 2 \succ \mathrm{T} 1 \stackrel{\mathrm{E} 1}{\text { ? }} \mathrm{E} 2 \succ \mathrm{E} 3 \quad$ ? $\mathrm{E} 4 \succ \mathrm{T} 4 \succ \mathrm{C} 1$ \\
\hline 8 & $\mathrm{C} 1 ?$ ? $\mathrm{C} 2 \succ \mathrm{T} 1$ ? $\mathrm{T} 2$ ? $\mathrm{T} 3 \succ \mathrm{T} 4 \succ \mathrm{E} 3 \quad$ ? $\mathrm{E} 4 \succ \mathrm{E} 1$ ? $\mathrm{E} 2$ \\
\hline 9 & $\mathrm{E} 3 \succ \mathrm{C} 1 \succ \mathrm{C} 2 \succ \mathrm{E} 4 \succ \mathrm{T} 1 \succ \mathrm{T} 3 \succ \mathrm{E} 1 \succ \mathrm{T} 4 \succ \mathrm{T} 2 \succ \mathrm{H}$ \\
\hline
\end{tabular}




\section{Multicriteria analysis methodology for sustainable energy planning}

The Stochastic Multicriteria Acceptability Analysis (SMAA) method (Lahdelma \& Salminen 2001; Lahdelma et al. 2003) was applied for evaluating the different heat production technologies. SMAA was applied because it is suitable for treating cardinal criteria measurements and ordinal preference information. The decision problem is defined as a set of $m$ alternatives that are measured in terms of $n$ criteria. The criteria measurements are represented as a matrix $\mathbf{x}=\left[x_{i j}\right]$ where $i$ identifies the alternative and $j$ the criterion. The alternatives are evaluated by an additive value function, which has the shape

$$
\mathrm{u}\left(x_{i}, \boldsymbol{w}\right)=w_{1} \cdot u_{i 1}+w_{2} \cdot u_{i 2}+\ldots+w_{\mathrm{n}} \cdot u_{i n} .
$$

Here, the partial values $u_{i j}$ are obtained by mapping actual criteria measurements $x_{i j}$ into the range $[0,1]$ where 0 is the worst outcome and 1 is best. The $w_{j}$ are importance weights for different criteria and they are used to represent preference information. The weights are non-negative and normalized so that their sum is 1 , i.e. the feasible weight space is defined as

$$
\mathrm{W}=\left\{\boldsymbol{w} \mid w_{j} \geq 0 \text { and } w_{1}+w_{2}+\ldots+w_{\mathrm{n}}=1\right\} .
$$

Both criteria and weight information can be imprecise, uncertain or partially missing. In SMAA such incomplete information is represented by suitable (joint) probability distributions:

- $f_{X}(\boldsymbol{x})$ the density function for stochastic criteria measurements.

- $f_{W}(\boldsymbol{w})$ the density function for stochastic importance weights.

\subsection{SMAA simulation}

Because all information is represented uniformly as distributions, this allows using efficient simulation techniques for analyzing the problem and deriving results about prospective solutions and their robustness. SMAA calculations are implemented by drawing simultaneously criteria measurements and weights from their distributions, applying the value function to rank the alternatives, and collecting statistics about the performance of the alternatives.

The following statistics are collected during the simulation:

$\mathrm{B}_{i r} \quad$ The number of times alternative $x_{i}$ obtained rank $r$.

$\mathrm{C}_{i k} \quad$ The number of times alternative $x_{i}$ was more preferred than $x_{k}$.

$\mathbf{W}_{i} \quad$ Sum of the weight vectors that made alternative $x_{i}$ most preferred.

\subsection{Basic SMAA measures}

The basic SMAA measures are computed based on the statistics collected during the simulation. These include rank acceptability indices, pairwise winning indices, central weight vectors, and confidence factors, as described in the following paragraphs. 
The rank acceptability index $b_{i}^{r}$ measures the variety of different preferences that place alternative $\mathbf{x}_{i}$ on rank $r$. It is the probability that the alternative obtains a certain rank. The first rank acceptability index $b_{i}^{1}$ is the probability that the alternative is most preferred. For inefficient alternatives the first rank acceptability index is zero. The rank acceptability indices are estimated from the simulation statistics (with $\mathrm{K}$ iterations) as

$$
b_{i}^{r} \approx \mathrm{B}_{i r} / \mathrm{K} \text {. }
$$

Alternatives with high acceptability for the best ranks are candidates for the most acceptable solution. If none of the alternatives receive high acceptability indices for the best ranks, it indicates a need to measure the criteria, preferences or both more accurately.

The pairwise winning index $c_{i k}$ is the probability for alternative $x_{i}$ being more preferred than $x_{k}$, considering the uncertainty in criteria and preferences (Leskinen et al.2006). The pairwise winning index is estimated as

$$
c_{i k} \approx \mathrm{C}_{i k} / \mathrm{K} \text {. }
$$

The pairwise winning indices are useful when comparing the mutual performance of two alternatives. Unlike the rank acceptability index, the pairwise winning index between each pair of alternatives is independent on all other alternatives. This means that the pairwise winning index can be used to form a ranking among the alternatives. The ranking is obtained by ordering the alternatives so that each alternative $x_{i}$ precedes all alternatives $x_{k}$ for which $c_{i k}>50 \%$ or some bigger threshold value. Observe that $c_{i k}+c_{k i} \leq 100 \%$. In many cases the formula holds as equality. Inequality occurs only if the alternatives sometimes are equally preferred during the simulation.

The central weight vector $\mathbf{w}_{i}^{c}$ is the expected centre of gravity of the weights that make an alternative most preferred. The central weight vector represents the preferences of a 'typical' DM supporting an alternative. The central weight vector for an alternative is estimated as

$$
\mathbf{w}_{i}^{c} \approx \mathbf{W}_{i} / \mathrm{B}_{i 1}
$$

The confidence factor $p_{i}^{c}$ is the probability for an alternative to obtain the first rank when its central weight vector is chosen. The confidence factors measure how robust choice for the first rank an alternative is if the DMs accept the central weight vector. Because the central weights are available only after the SMAA simulation, a second simulation is needed to compute the confidence factors. The confidence factors are computed from additional statistics:

$\mathrm{P}_{i} \quad$ The number of times alternative $x_{i}$ was most preferred using weights $\mathbf{w}_{i}^{c}$.

The confidence factor is then estimated as

$$
p_{i}^{c} \approx \mathrm{P}_{i} / \mathrm{K}
$$

Observe that the confidence factor is equal to the first rank acceptability index computed based on precise and unanimous preference information. 


\subsection{Modelling uncertain criteria and preference information}

The criteria can be measured on cardinal or ordinal scales. In this application, cardinal criteria measurement was applied. For each cardinal criterion, the partial utilities $u_{i j}$ were computed from the actual (stochastic) criteria measurements $x_{i j}$ through linear scaling of the range between the best and worst criteria measurements, $u_{i j}=\left(x_{i j}-x_{j}^{\text {worst }}\right) /\left(x_{j}^{\text {best }}-x_{j}^{\text {worst }}\right)$. When the cardinal criteria measurements $x_{i j}$ are stochastic quantities, so are the partial values $u_{i j}$.

Weight information is represented by an appropriate joint distribution in W. In the absence of weight information, any feasible weights are equally possible, which is represented by a uniform distribution $f_{W}(\boldsymbol{w})$. Figure 2a illustrates the uniform weight distribution in the 3-dimensional case. Uniformly distributed normalized weights need to be generated using a special technique (Tervonen \& Lahdelma 2007). First $n$ - 1 independent uniformly distributed random numbers in the interval $[0,1]$ are generated and sorted together with 0 and 1 into ascending order to get $0=r_{0} \leq r_{1} \leq \ldots \leq r_{n}$ $=1$. From these numbers the weights are computed as the intervals $w_{1}=r_{1}-r_{0}, w_{2}=r_{2}-r_{1}, \ldots, w_{n}=$ $r_{n}-r_{n-1}$. It is obvious that the resulting weights will be non-negative and normalized (2). For the proof that the resulting joint distribution is uniform, see David (1970). Figure $2 b$ illustrates generation of uniformly distributed weights in the 3-criterion case, projected on the $\left(w_{1}, w_{2}\right)$ plane where $w_{3}=1-w_{1}-w_{2}$.
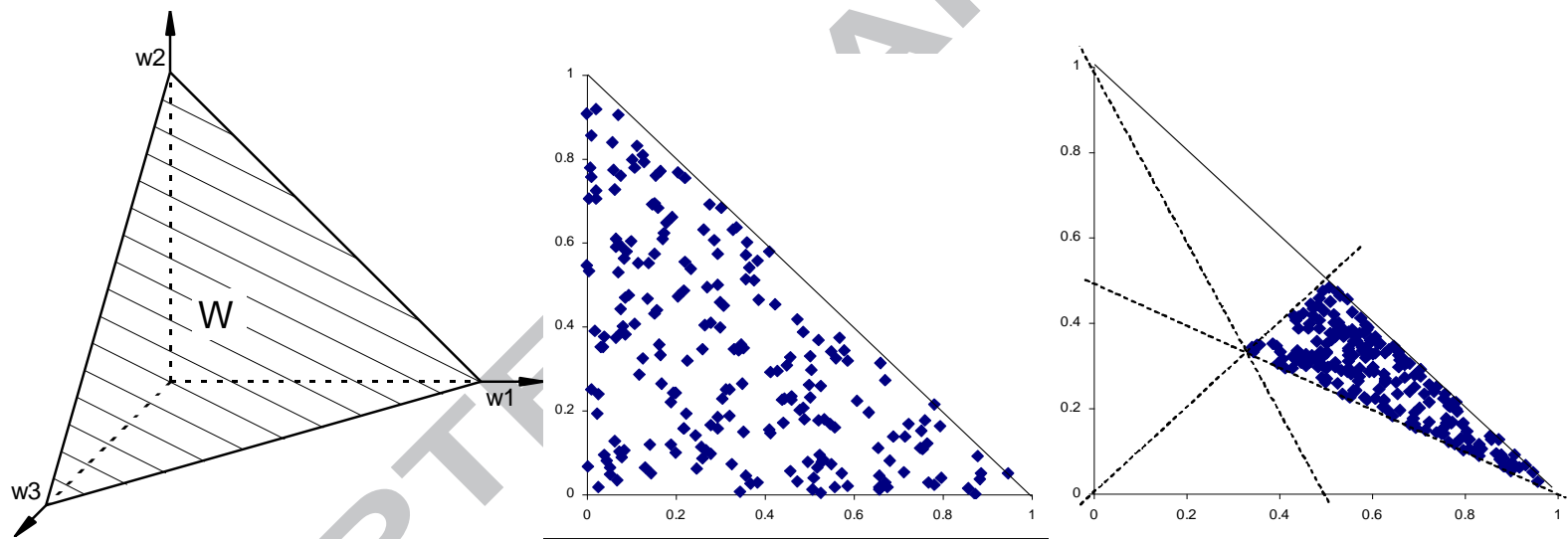

Figure 2. a) Feasible weight space in the 3-criterion case. b) Sampling uniformly distributed weights in the 3-criterion case projected on the $\left(w_{1}, w_{2}\right)$ plane. c) Uniformly distributed weights with ordinal weight information $w_{1} \geq w_{2} \geq w_{3}$.

Preference information is treated by restricting the uniform weight distribution with additional constraints. Weight constraints can be implemented by modifying the weight generation procedure to reject weights that do not satisfy the constraints. In most cases, the simple rejection technique is sufficiently efficient. In some cases, the more efficient Markov Chain Monte Carlo simulation technique is necessary (Tervonen et al. 2013).

In this application, ordinal weight information was applied. As described in section 2.4, each expert specified a partial importance order for the criteria. If the expert considered criterion $j$ more important than criterion $k$, that resulted in inequality constraint $w_{j} \geq w_{k}$ between the weights. Treating this kind of weight constraints is implemented efficiently by sorting the uniformly generated weights with minimal number of adjacent swaps so that all constraints are satisfied. Figure $2 \mathrm{c}$ illustrates ordinal weight information in the 3-criterion case. 


\subsection{Treating conflicting preference information}

In earlier SMAA applications, group preference information has been provided as a common partial order of preference for the criteria formed collectively by the DMs, or as form upper and lower bounds for criteria weights from independently by the DMs.

In the current application, the experts provided their partial order of preference for the criteria independently. Because the orders preference of different experts were in some cases highly conflicting (see Table 4), combining the information into a single partial order would result in nearly vacuous importance order $\left(w_{1} ? w_{2} ? \ldots ? w_{n}\right)$. For example, $\mathrm{C} 1$ can be either the most or least important criterion. However, E3 is consistently at least as important as E4.

For this reason, a new way to treat the conflicting preference information in SMAA was developed. To give equal significance to the preferences of each expert, the weights were generated so that during each iteration of the simulation, first one of the experts was randomly selected. Then the importance weights were generated according to his/her (ordinal) preference information. The advantage of this approach is that all preferences are considered, but preferences supported by multiple experts influence the analysis more.

\section{Results}

The following presents the results of analyzing the problem using SMAA based on uncertain criteria measurements (Table 3 ) and ordinal weight information by the experts (Table 4).

Figure 3 shows the rank acceptability indices for the alternatives. The rank acceptability indices describe the probabilities for each alternative to obtain a certain rank when considering uncertain criteria measurements and ordinal preferences. Alternative A18 receives highest first rank acceptability of $36 \%$. Second highest is A20 with $30 \%$ followed by A9 with 8\%, A15 with 6\%, and A6 with 5\%. These alternatives are candidates for most acceptable solutions because they receive relatively high acceptability for the best ranks. The last rank is obtained most often by A21 with 94\% and A13 with 5\%. Thus, the rank acceptability indices identify roughly the most and least acceptable alternatives. However, these indices do not determine a unique preference order for all alternatives. 


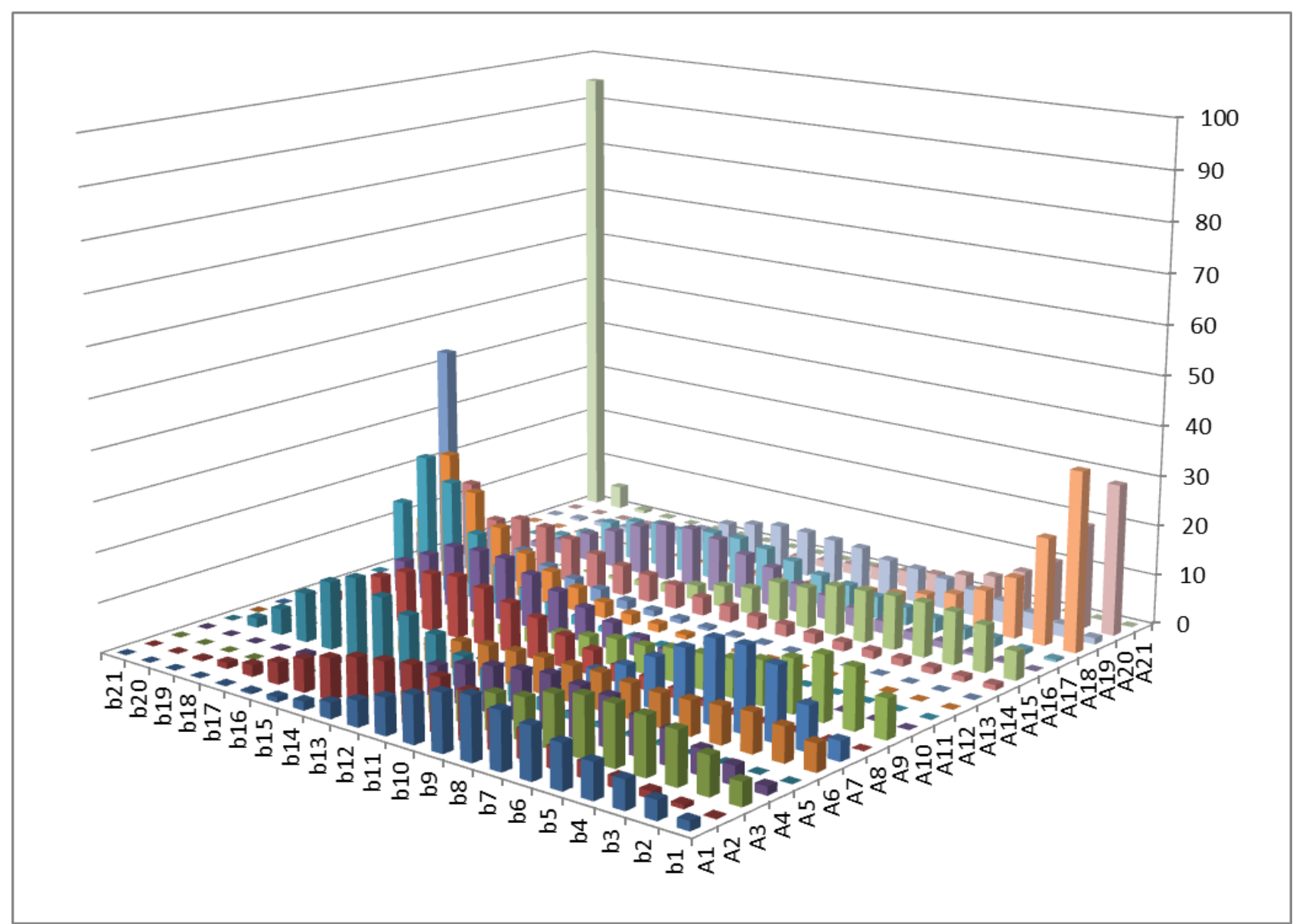

Figure 3. Rank acceptability indices of alternatives (\%).

A probabilistic ranking of alternatives can be obtained using the pairwise winning indices shown in Table 5. Each row lists the probabilities for an alternative to be more preferred than each of the other alternatives. In the table, the alternatives are sorted topologically so that the alternative with higher index is before the alternatives with lower indices. In this case topological sorting produces a complete ranking. However, the ranking is based on uncertain criteria and partly conflicting preference information. For example, the pairwise winning indices between A18 and A20 are 55\% versus $45 \%$. This means that each of these alternatives have reasonably high probability of being more preferred. More accurate and unanimous information is needed to produce a more deterministic ranking. Still, even with the current information, the pairwise winning indices near $100 \%$ reveal that the high-end alternatives are superior to the low-end alternatives. 
Table 5. Pairwise winning indices of alternatives (\%). Alternatives are sorted topologically.

\begin{tabular}{|c|c|c|c|c|c|c|c|c|c|c|c|c|c|c|c|c|c|c|c|c|c|}
\hline & 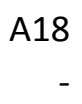 & 55 & 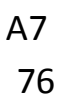 & 76 & 78 & 80 & & & 7 & 92 & 94 & & 97 & & 99 & & 96 & $9 y$ & 100 & & \\
\hline & 15 & - & 72 & 2 & 74 & 5 & 32 & 80 & 4 & 88 & & 93 & 95 & & o & & & & & 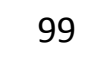 & \\
\hline & 24 & 8 & _. & 53 & 58 & 0 & & 68 & 5 & 83 & & ด० & & & & & & 9 & 100 & 99 & $0 C$ \\
\hline & 2 & 8 & 7 & - & 53 & 4 & UJ & 63 & 6 & 76 & & 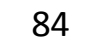 & 37 & & & & & 7 & 0 & & \\
\hline & 22 & 6 & 2 & 47 & - & 51 & 1 & 62 & 6 & 76 & & 84 & 30 & & & & & 8 & 99 & & \\
\hline & 20 & 25 & 40 & 6 & 49 & - & 6 & 60 & 7 & 75 & 5 & 86 & 89 & & 95 & & 89 & 99 & 99 & 99 & \\
\hline & 1 & 8 & 26 & 37 & 36 & 35 & - & 51 & 4 & 66 & 8 & 79 & 84 & & $\perp$ & & 81 & 98 & 99 & 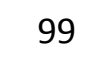 & . \\
\hline & 17 & 20 & 32 & 37 & 38 & 40 & 49 & - & 2 & 62 & 67 & 74 & 77 & 86 & 89 & 81 & 84 & 96 & 97 & 7 & 10 \\
\hline & 13 & 16 & 5 & 4 & 34 & 33 & 46 & 48 & - & 62 & 72 & 76 & 79 & 87 & 89 & 92 & 84 & 97 & 99 & 9 & 0 \\
\hline & 8 & 2 & 7 & t & 24 & 5 & 34 & 38 & 8 & - & & 2 & 67 & & 82 & & 33 & 2 & 95 & & \\
\hline & 6 & 9 & 10 & 22 & 16 & 15 & 22 & 33 & 8 & 43 & & 58 & 63 & & 77 & 84 & 77 & 93 & 97 & 6 & . \\
\hline & 5 & 7 & 10 & 16 & 16 & 14 & 21 & 26 & 4 & 38 & 42 & - & 53 & 65 & 70 & 71 & 71 & 91 & 93 & 6 & 10 \\
\hline & 3 & 5 & 6 & & 10 & 11 & 16 & 24 & 1 & 33 & & 47 & & 64 & 69 & & ( & 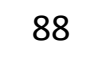 & & & \\
\hline & 2 & 3 & 2 & 7 & 7 & 7 & 10 & 14 & 3 & 20 & & 35 & 6 & & 55 & 55 & 61 & 88 & 33 & & 0 \\
\hline & 1 & 2 & 2 & 2 & $\sigma$ & 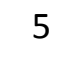 & 9 & 11 & 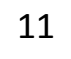 & 18 & 3 & 30 & 31 & 4 & 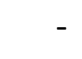 & 51 & 58 & 0 & 00 & & 10 \\
\hline & 2 & 3 & 1 & & 3 & 1 & 5 & 12 & & 17 & & 29 & 30 & 4 & 49 & & 58 & 4 & & & 1 \\
\hline & 4 & 6 & 7 & & 8 & 1 & 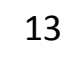 & 17 & 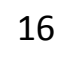 & & $V$ & 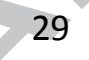 & 1 & & 12 & & & 4 & 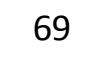 & & 10 \\
\hline & 1 & 1 & 1 & J & 2 & + & 2 & 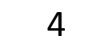 & 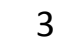 & & 7 & 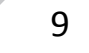 & 12 & 22 & $2 \pi$ & & 36 & & 6 & & \\
\hline & 0 & 1 & . & & & 1 & & & & & & & & & & & 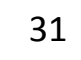 & & & 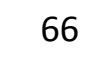 & \\
\hline & 0 & 1 & 1 & 2 & 1 & $\perp$ & & & & & 4 & 4 & I & 14 & 15 & & 26 & 27 & 4 & & \\
\hline & & 0 & 0 & & $v$ & 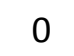 & & 0 & & 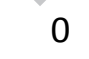 & & & v & & & & & & & & \\
\hline
\end{tabular}

Table 6 presents the confidence factors and central weight vectors for the alternatives. The confidence factor is the probability that an alternative is most preferred with its central weights, considering the uncertainty of criteria measurements. Note that central weights and confidence factors for A8, A11 and A21 are undefined, because these alternatives are inefficient, i.e. no feasible weights make them most preferred. Observe that the confidence factors for all alternatives, even for the best ones (A18, A20) are quite low (49\%, 38\%). This means that the uncertainty in criteria measurements make it impossible to identify a single best alternative reliably. To obtain more conclusive results, it is therefore necessary to provide more accurate criteria measurements just providing more accurate preference information is not sufficient. 
Table 6. Confidence factors and central weights for efficient alternatives (\%).

\begin{tabular}{|c|c|c|c|c|c|c|c|c|c|c|}
\hline Alt & $p^{c}$ & $\mathrm{C} 1$ & $\mathrm{C} 2$ & $\mathrm{~T} 1$ & $\mathrm{~T} 2$ & T3 & T4 & E1 & E2 & E3 \\
\hline A1 & 7 & 8 & 18 & 21 & 12 & 7 & 10 & 4 & 1 & 14 \\
\hline A2 & 1 & 6 & 20 & 23 & 14 & 6 & 13 & 3 & 1 & 10 \\
\hline A3 & 9 & 15 & 20 & 16 & 8 & 6 & 10 & 3 & 1 & 15 \\
\hline A4 & 4 & 14 & 21 & 17 & 9 & 6 & 12 & 2 & 1 & 13 \\
\hline A5 & 1 & 1 & 12 & 41 & 20 & 4 & 5 & 3 & 0 & 11 \\
\hline A6 & 7 & 26 & 17 & 11 & 8 & 7 & 10 & 3 & 3 & 11 \\
\hline A7 & 6 & 17 & 20 & 16 & 9 & 7 & 8 & 3 & 2 & 12 \\
\hline A8 & - & - & - & - & - & - & - & - & - & - \\
\hline A9 & 12 & 26 & 18 & 11 & 10 & 8 & 9 & 3 & 2 & 8 \\
\hline $\mathrm{A} 10$ & 0.0 & 25 & 19 & 11 & 11 & 7 & 5 & 4 & 7 & 9 \\
\hline A11 & - & - & - & - & - & - & - & - & - & - \\
\hline $\mathrm{A} 12$ & 0.4 & 18 & 17 & 6 & 2 & 4 & 2 & 3 & 1 & 36 \\
\hline $\mathrm{A} 13$ & 0.2 & 12 & 61 & 11 & 1 & 2 & 1 & 0 & 0 & 11 \\
\hline A14 & 4 & 3 & 26 & 14 & 14 & 15 & 3 & 7 & 5 & 10 \\
\hline A15 & 9 & 11 & 22 & 16 & 10 & 9 & 10 & 4 & 3 & 11 \\
\hline A16 & 0.5 & 6 & 32 & 8 & 10 & 14 & 7 & 5 & 4 & 9 \\
\hline A17 & 2 & 23 & 20 & 9 & 3 & 5 & 6 & 3 & 2 & 22 \\
\hline A18 & 49 & 19 & 21 & 12 & 9 & 9 & 10 & 4 & 3 & 8 \\
\hline A19 & 4 & 5 & 27 & 13 & 14 & 16 & 3 & 7 & 5 & 6 \\
\hline A20 & 38 & 21 & 18 & 14 & 9 & 8 & 9 & 4 & 3 & 10 \\
\hline
\end{tabular}

A21

The central weights in Table 6 and Figure 4 represent typical preferences that make each alternative most preferred. The central weights were computed as average of the experts' partly conflicting preferences. Thus, none of the central weight vectors is consistent with the preferences of all experts. In fact, some weight vectors may be in conflict with each expert's preferences. For some criteria, such as $\mathrm{C} 2, \mathrm{~T} 1$, and E3 the variation in central weighs is large, which means these criteria discriminate some alternatives strongly. For criteria E1 and E2 all the central weights are small, because none of the experts consider them very important. The central weights of the most acceptable alternatives A18, A20, A9, A15, and A6 cluster in general near the middle of all central weights. In contrast, certain less acceptable alternatives are supported by extremely high or low weight for some criteria. For example, A13 receives $61 \%$ central weight for criterion $\mathrm{C} 2$ and low weights for criteria T2, T3, T4, E1, E2 and E4. 


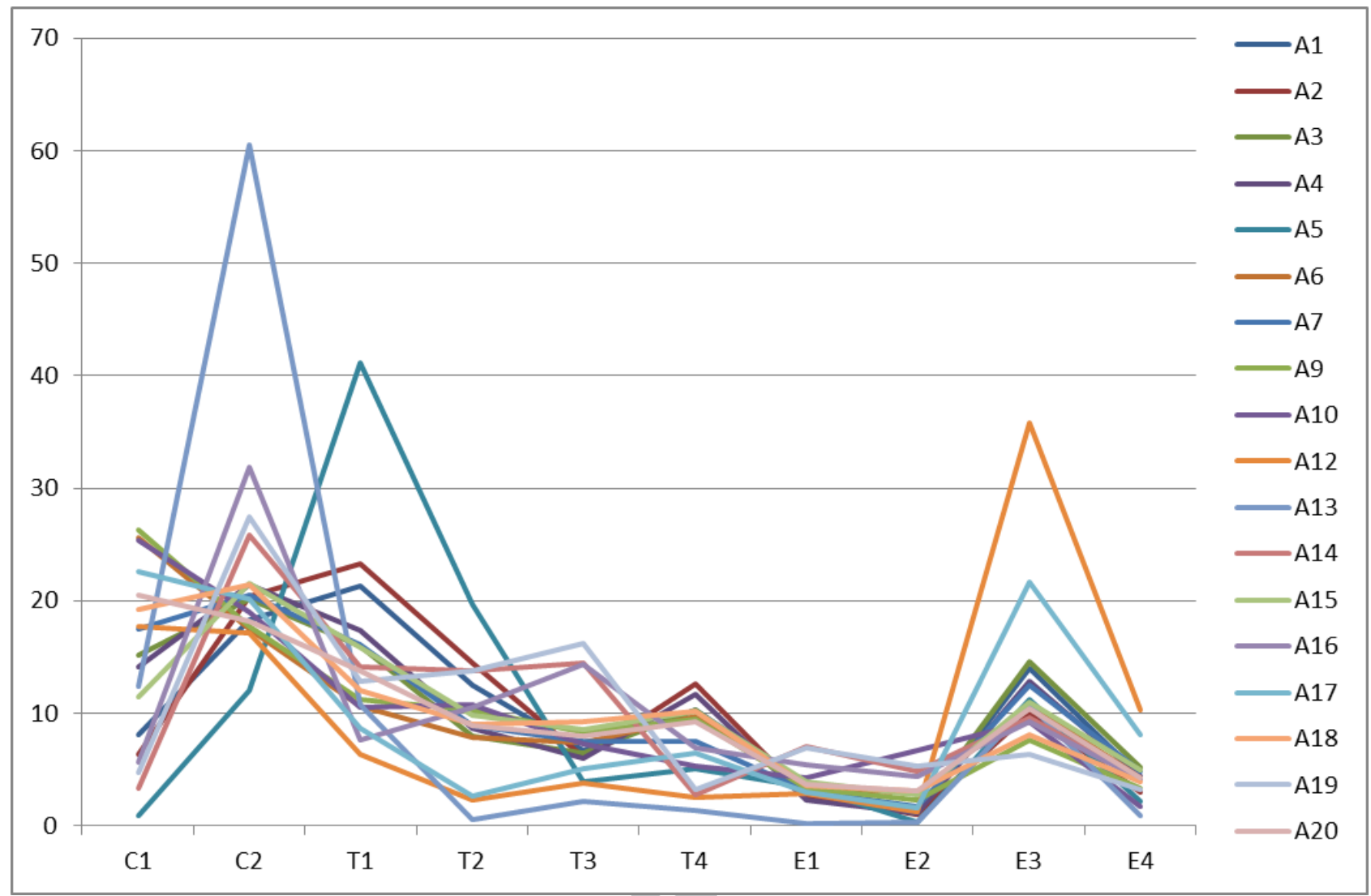

Figure 4. Central weights of alternatives (\%).

\section{Discussion}

Although the analysis did not reveal a single clearly superior alternative, this is not a problem. Several of the most acceptable technologies can be implemented together, as long as it does not lead to overcapacity. More detailed planning of the capacities and locations of such plants is required. Detailed planning should optimize the overall DH system performance based on long-term estimates of variable heat demand.

CCS technology (A21) was ranked last. CCS technology is not mature enough for commercial application in DH production, because there not enough evidence on the reliability of the technology and the costs are very high. Also the large space demand of CCS is not ideal for peak heat plants.

Among the least favorable alternatives were all solar heat related alternatives (A11, A12, A13). Under Finnish climate and other local conditions, utilization of solar heat is currently not a viable carbon-neutral alternative for large scale DH production largely due to the time discrepancy of production and demand. Solar heat is mostly available on sunny summer days when heat demand is minimal, and not available during the cold winter. A seasonal seasonal storage, as in A11, is expensive and implies significant losses.

Some assumptions are necessary when applying SMAA. Uniform distributions were used to represent uncertain criteria measurements. SMAA allows using arbitrary distributions, but earlier studies have indicated that the distribution shape has typically very little effect on the results. The DM's preference structure was modelled using the linear value function. More complicated 
functions can be easily used in SMAA. SMAA has been found to be robust with respect to different function shapes (Lahdelma \& Salminen 2012).

\section{Conclusion}

In this study, potentially feasible carbon-neutral DH technologies for the city of Helsinki were evaluated using a multicriteria decision support approach with a group of experts. The results identified several favorable technologies for carbon-neutral $\mathrm{DH}$ production with the view of the peak heat demand in mind.

According to the analysis, the most acceptable potential technologies are short-term heat storages (A18) for cutting the peak heat demand, and electric boilers (A20) for situations where excess carbon-neutral electricity is available. Combustion of biodiesel in existing oil-boilers (A9), large scale ground source heat pumps (A15), and combustion of biogas in existing gas boilers (A6) also obtained high ranking.

The Stochastic Multicriteria Acceptability Analysis (SMAA) was used in this case. SMAA is particularly suitable for this kind of problem because it is able to handle uncertain, imprecise or incomplete information with flexibility using suitable probability distributions. Because each expert expressed different preferences, a new way to treat the conflicting preferences was developed within this application.

The applied methodology is suitable for similar evaluation problems. However, the alternatives and criteria are case-specific.

\section{Funding}

This research did not receive any specific grant from funding agencies in the public, commercial, or not-for-profit sectors.

\section{References}

Alanne K., Salo A., Saari A., Gustafsson S.-I., 2007. Multi-criteria evaluation of residential energy supply systems. Energy and Buildings 39: 1218-1226.

Burer M., Tanaka K., Favrat D., Yamada K., 2003. Multi-criteria optimization of a district cogeneration plant integrating a solid oxide fuel cell-gas turbine combined cycle, heat pumps and chillers. Energy 28: 497-518.

Catalina T., Virgone J., Blanco E., 2011. Multi-source energy systems analysis using a multicriteria decision aid methodology. Renewable Energy 36: 2245-2252.

Cavallaro F., 2009. Multi-criteria decision aid to assess concentrated solar thermal technologies. Renewable Energy 34:1678-1685.

Cherni J.A., Dyner I., Henao F., Jaramillo P., Smith R., Font R.O., 2007. Energy supply for sustainable rural livelihoods. A multi-criteria decision-support system. Energy Policy 35: 14931504. 
Chinese D., Nardin G., Saro O., 2011. Multi-criteria analysis for the selection of space heating systems in an industrial building. Energy 36: 556-565.

Connolly D., Lund H., Mathiesen B.V., Werner S., Möller B., Persson U., Boermans T., Trier D., Østergaard P.A., Nielsen S., 2014. Heat Roadmap Europe: Combining DH with heat savings to decarbonise the EU energy system. Energy Policy 65: 475-489.

David H.A., 1970. Order Statistics. Wiley, New York.

Dombi M., Kuti I., Balogh P., 2014. Sustainability assessment of renewable power and heat generation technologies. Energy Policy 67: 264-271.

Ghafghazi S., Sowlati T., Sokhansanj S., Melin S., 2010a. A multicriteria approach to evaluate district heating system options. Applied Energy: 87(4): 1134-1140.

Ghafghazi S., Sowlati T., Sokhansanj S., Melin S., 2010b. Techno-economic analysis of renewable energy source options for a district heating project. International Journal of Energy Research 34(12): 1109-1120.

Grujić M., Ivezić D., Živković M., 2014. Application of multi-criteria decision-making model for choice of the optimal solution for meeting heat demand in the centralized supply system in Belgrade. Energy 67: 341-350.

Helen Ltd., 2015a. A Carbon Neutral Future. https://www.helen.fi/en/helenoy/responsibility/carbon-neutral-future/ [Accessed 19.05.16].

Helen Ltd., 2015b. Energy production in Helsinki. https://www.helen.fi/en/helen-oy/aboutus/energy-production/ [Accessed 19.05.16].

Helen Ltd., 2015c. District Heating in Helsinki - 07.01.2015. Internal document. Base map provided by Real Estate Department, City of Helsinki.

Helen Ltd., 2015d. Annual report 2015. https://www.helen.fi/en/annual-report/annualreport2015/konsernin-vuosi/liiketoimintavuosi/ [Accessed 19.05.16].

Helen Ltd., 2015e. Helen invests in renewable energy and distributed energy production. https://www.helen.fi/en/news/2015/helen-invests-in-renewable-energy-and-distributed-energyproduction/ [Accessed 19.05.16].

Hokkanen J., Lahdelma R., Miettinen K., Salminen P., 1998. Determining the implementation order of a general plan by using a multicriteria method. Journal of Multi-Criteria Decision Analysis 7(5): 273-284.

Hokkanen J., Lahdelma R., Salminen P., 1999. A multiple criteria decision model for analyzing and choosing among different development patterns for the Helsinki cargo harbor. Socio-Economic Planning Sciences 33: 1-23.

Hokkanen J., Lahdelma R., Salminen P., 2000. Multicriteria decision support in a technology competition for cleaning polluted soil in Helsinki. Journal of Environmental Management 60: 339348.

Jovanovic M., Afgan N., Bakic V., 2010. An analytical method for the measurement of energy system sustainability in urban areas. Energy 35: 3909-3920. 
Kangas A., Kangas J., Lahdelma R., Salminen P., 2006. Using SMAA-2 method with dependent uncertainties for strategic forest planning. Forest Policy and Economics 9(2): 113-125.

Kangas J., Hokkanen J., Kangas A., Lahdelma R., Salminen P., 2003. Applying stochastic multicriteria acceptability analysis to forest ecosystem management with both cardinal and ordinal criteria. Forest Science 49(6): 928-937.

Kangas J., Store R., Kangas A., 2005. Socioecological landscape planning approach and multicriteria acceptability analysis in multiple-purpose forest management. Forest Policy and Economics 7(4): 603-614.

Karabay S., Kose E., Kabak M., Ozceylan E., 2016. Mathematical model and stochastic multicriteria acceptability analysis for facility location problem. PROMET - Traffic \&Transportation 28(3): 245-256.

Keeney, R.L. and Raiffa H., 1976. Decisions with multiple objectives: Preferences and value tradeoffs. John Wiley \& Sons, New York.

Khorasaninejad E., Fetanat A. Hajabdollahi H., 2016. Prime mover selection in thermal power plant integrated with organic Rankine cycle for waste heat recovery using a novel multi criteria decision making approach. Applied Thermal Engineering 102: 1262-1279.

Kontu K., Rinne S., Olkkonen V., Lahdelma R., Salminen P., 2015. Multicriteria evaluation of heating choices for a new sustainable residential area. Energy and Buildings 93: 169-179.

Kumar A., Sah B., Singh A.R., Deng Y., He X.N. Kumar P., Bansal R.C. 2017. A review of multi criteria decision making (MCDM) towards sustainable renewable energy development. Renewable \& Sustainable Energy Reviews 69: 596-609.

Lahdelma R., Salminen P., Hokkanen J., 2000. Using Multicriteria Methods in Environmental Planning and Management. Environmental Management 26(6): 595-605.

Lahdelma R. and Salminen P., 2001. SMAA-2: Stochastic multicriteria acceptability analysis for group decision making. Operations Research 49(3): 444-454.

Lahdelma R. and Salminen P., 2012. The shape of the utility or value function in Stochastic Multicriteria Acceptability Analysis. OR Spectrum 34: 785-802.

Lahdelma R., Hokkanen J., Salminen P., 1998. SMAA - Stochastic Multiobjective Acceptability Analysis. European Journal of Operational Research 106(1): 137-143.

Lahdelma R., Miettinen K., Salminen P., 2003. Ordinal criteria in stochastic multicriteria acceptability analysis (SMAA). European Journal of Operational Research 147(1):117-127.

Lahdelma R., Salminen P., 2008a. Multicriteria decision analysis for choosing the remediation method for a landfill based on mixed ordinal and cardinal information. In I. Linkov, E. Ferguson, V.S. Magar (eds) Real-Time and Deliberative Decision Making: Application to Emerging Stressors. NATO Science for Peace and Security Series - C: Environmental Security, Springer, Dordreht, 379-396.

Lahdelma R., Salminen P., 2008b. Ordinal measurements with interval constraints in the EIA process for siting a waste storage area. In I. Linkov, E. Ferguson, V.S. Magar (eds) Real-Time and Deliberative Decision Making: Application to Emerging Stressors. NATO Science for Peace and Security Series - C: Environmental Security, Springer, Dordreht, 397-414. 
Lahdelma R., Salminen P., 2010. Stochastic multicriteria acceptability analysis (SMAA). In M. Ehrgott, J.R. Figueira, S. Greco (eds) Trends in Multiple Criteria Decision Analysis. International Series in Operations Research and Management Science, Springer, 142: 285-316.

Lahdelma R., Salminen P., 2016. SMAA in robustness analysis. In M. Doumpos, C. Zopunidis, E. Grigoroudis (eds) Robustness Analysis in Decision Aiding, Optimization, and Analytics. International Series in Operations Research \& Management Scienc, Springer, 241: 1-20.

Lahdelma R., Salminen P., Hokkanen J., 2002. Locating a waste treatment facility by using stochastic multicriteria acceptability analysis with ordinal criteria. European Journal of Operational Research 142: 345-356.

Lahdelma R., Salminen P., Simonen A., Hokkanen J., 2001. Choosing a reparation method for a landfill using the SMAA-O multicriteria method. In Köksalan, Zionts (eds) Multiple criteria decision making in the new millenium, Lecture Notes in Economics and Mathematical Systems 507:380-389.

Leskinen P., Viitanen J., Kangas A., Kangas J., 2006. Alternatives to incorporate uncertainty and risk attitude in multicriteria evaluation of forest plans. Forest Science 52(3): 304-312.

Lund H., Möller B., Mathiesen B.V., Dyrelund A., 2010. The role of district heating in future renewable energy systems. Energy 35(3): 1381-1390.

Lund H., Werner S., Wiltshire R., Svendsen S., Thorsen J.E., Hvelplund F., Mathiesen B.V., 2014. 4th Generation District Heating (4GDH): Integrating smart thermal grids into future sustainable energy systems. Energy 68: 1-11.

Mamlook R., Akash B.A., Nijmeh S., 2001 Fuzzy sets programming to perform evaluation of solar systems in Jordan. Energy Conversion and Management 42: 1717-1726.

Mardani A., Zavadskas E.K., Khalifah Z., Zakuan N., Jusoh A., Nor K.M., Khoshnoudi M. 2017. A review of multi-criteria decision-making applications to solve energy management problems: Two decades from 1995 to 2015. Renewable \& Sustainable Energy Reviews 71: 216-256.

Matteson S., 2014. Methods for multi-criteria sustainability and reliability assessments of power systems. Energy 71: 130-136.

Maxim A., 2014. Sustainability assessment of electricity generation technologies using weighted multi-criteria decision analysis. Energy Policy 65: 284-297.

Menou A., Benallou A., Lahdelma R., Salminen P., 2010. Decision support for centralizing cargo at a Moroccan airport hub using stochastic multicriteria acceptability analysis. European Journal of Operational Research 204: 621-629.

Mroz T.M. 2008. Planning of community heating systems modernization and development. Applied Thermal Engineering 28(14-15): 1844-1852.

Okul D., Gencer C., Aydogan E., 2014. A Method Based on SMAA-Topsis for Stochastic MultiCriteria Decision Making and a Real-World Application. International Journal of Information Technology \& Decision Making 13(5):957-978. 
Omitaomu O.A., Blevins B.R., Jochem W.C., Mays G.T., Belles R., Hadley S.W., Harrison T.J., Bhaduri B.L., Neish B.S., Rose A.N., 2012. Adapting a GIS-based multicriteria decision analysis approach for evaluating new power generating sites. Applied Energy 96: 292-301.

Østergaard P.A., Mathiesen B.V., Möller B., Lund H., 2010. A renewable energy scenario for Aalborg Municipality based on low-temperature geothermal heat, wind power and biomass. Energy 35(12): 4892-4901.

Pesola A., Serkkola A., Lahdelma R., Salminen P., 2014. Multicriteria evaluation of alternatives for remote monitoring systems of municipal buildings. Energy and Buildings 72: 229-237.

Pilavachi P.A., Stephanidis S.D., Pappas V.A., Afgan N.H. 2011. Multi-criteria evaluation of hydrogen and natural gas fuelled power plant technologies. Applied Thermal Engineering 29(1112): $2228-2234$

Pohekar S.D., Ramachandran M., 2004. Application of multi-criteria decision making to sustainable energy planning - A review. Renewable and Sustainable Energy Reviews 8: 365-381.

Rahman M.M., Paatero J., Lahdelma R., 2013. Evaluation of choices for sustainable rural electrification in developing countries: A multicriteria approach. Energy Policy 59: 589-599.

Rahman M.M., Paatero J.V., Lahdelma R., Wahid M.A., 2016. Multicriteria-based decision aiding technique for assessing energy policy elements-demonstration to a case in Bangladesh. Applied Energy 164: 237-244.

Ribeiro F., Ferreira P., Araújo M., 2013. Evaluating future scenarios for the power generation sector using a Multi-Criteria Decision Analysis (MCDA) tool: The Portuguese case. Energy 52: 126-136.

Rocchi L., 2012. Using stochastic multi-criteria acceptability analysis methods in SEA: an application to the Park of Trasimeno (Italy). Journal of Environmental Planning and Management 55(2):177-189.

Sánchez-Lozano J.M., García-Cascales M.S., Lamata M.T., 2016. GIS-based onshore wind farm site selection using Fuzzy Multi-Criteria Decision Making methods. Evaluating the case of Southeastern Spain. Applied Energy 171: 86-102.

Santoyo-Castelazo E., Azapagic A., 2014. Sustainability assessment of energy systems: Integrating environmental, economic and social aspects. Journal of Cleaner Production 80: 119-138.

Scheffler A., Roth T., Ahlf W., 2014. Sustainable decision making under uncertainty: A case study in dredged material management. Environmental Sciences Europe 26:7.

Si J., Marjanovic-Halburd L., Nasiri F., Bell S. 2016. Assessment of building-integrated green technologies: A review and case study on applications of Multi-Criteria Decision Making (MCDM) method. Sustainable Cities and Society 27: 106-115.

St1, 2016. St1 begins the drilling of geothermal deep-rock wells in Otaniemi, Espoo. ST1 Ltd. http://www.st1.eu/news/st1-begins-the-drilling-of-geothermal-deep-rock-wells-in-otaniemi-espoo

Stein E.W., 2013. A comprehensive multi-criteria model to rank electric energy production technologies. Renewable and Sustainable Energy Reviews 22: 640-654. 
Tervonen T., Figueira J., 2008. A survey on stochastic multicriteria acceptability analysis methods. Journal of Multi-Criteria Decision Analysis 15(1-2): 1-14.

Tervonen T., Lahdelma R., 2007. Implementing stochastic multicriteria acceptability analysis. European Journal of Operational Research 178(2): 500-513.

Tervonen T., Linkov I., Figueira J.R., Steevens J., Chappel M., Merad M., 2009. Risk-based classification system of nanomaterials. Journal of Nanoparticle Research 11(4): 757-766.

Tervonen T., van Valkenhoef E., Bastürk N., Postmus D., 2013. Hit-and-run enables efficient weight generation for simulation based multiple criteria decision analysis. European Journal of Operational Research 224(3): 552-559.

Tervonen T., van Valkenhoef G., Buskens E., Hillege H.L., Postmus D., 2011. A stochastic multicriteria model for evidence-based decision making in drug benefit-risk analysis. Statistics in Medicine 30(12):1419-1428.

Tsoutsos T., Drandaki M., Frantzeskaki N., Iosifidis E., Kiosses I., 2009. Sustainable energy planning by using multi-criteria analysis application in the island of Crete. Energy Policy 37: 15871600 .

van Valkenhoef G., Tervonen T., Zhao J., de Brock B., Hillege H.L., Postmus D., 2012. Multicriteria benefit-risk assessment using network meta-analysis. Journal of Clinical Epidemiology 65(4): 394-403.

Vučijak B., Kupusović T., Midžić-Kurtagić S., Cerić A., 2013. Applicability of multicriteria decision aid to sustainable hydropower. Applied Energy 101: 261-267.

Wang E., 2015. Benchmarking whole-building energy performance with multi-criteria technique for order preference by similarity to ideal solution using a selective objective-weighting approach. Applied Energy 146: 92-103.

Wang H., Jiao W., Lahdelma R., Zhu C., Zou P.-H., 2015a. Stochastic Multicriteria Acceptability Analysis for Evaluation of Combined Heat and Power Units. Energies 8: 59-78.

Wang H., Lahdelma R., Wang X., Jiao W., Zhu C., Zou P., 2015b. Analysis of the location for peak heating in CHP based combined district heating systems. Applied Thermal Engineering 87: 402411.

Wang J., Jing Y., Zhang C., Zhao J., 2009. Review on multi-criteria decision analysis aid in sustainable energy decision-making. Renewable and Sustainable Energy Reviews, 13(9): 22632278. 


\section{Highlights}

- Heat storages and electric boilers are best solutions for peak-load situations

- CCS technology is too immature, unreliable, costly, and has too large space demand

- Solar heat is unfavorable at Helsinki latitude due to bad coincidence with demand

- Multicriteria method was developed for treating conflicting experts' preferences 